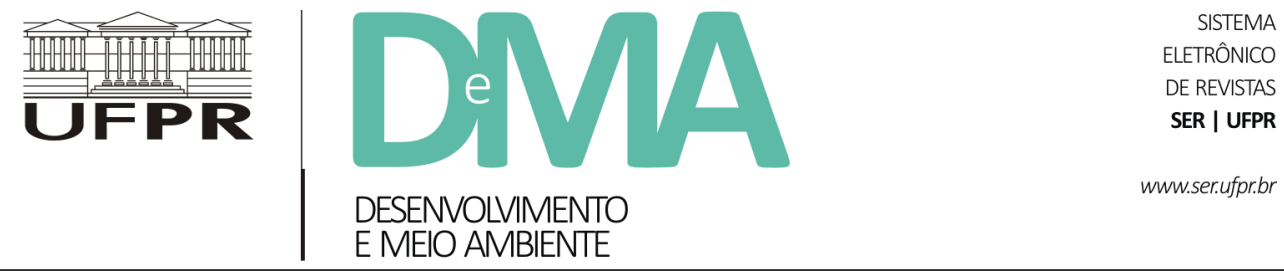

\title{
Cyklistforbundet: da ecossocioeconomia à convivencialidade
}

\section{Cyklistforbundet: from Eco-social Economy to Conviviality}

\author{
Jorge Gustavo Barbosa de OLIVEIRA ${ }^{1}$, Janaina Mayara Müller da SILVA ${ }^{1 *}$, Lars BOHN², Carlos Alberto Cioce \\ SAMPAIO ${ }^{1,3,4}$ \\ ${ }^{1}$ Programa de Pós-Graduação em Desenvolvimento Regional, Universidade Regional de Blumenau (FURB), Blumenau, SC, Brasil. \\ ${ }^{2}$ Roskilde University (RUC), Roskilde, Dinamarca. \\ ${ }^{3}$ Programa de Pós-Graduação em Gestão Ambiental, Universidade Positivo (UP), Curitiba, PR, Brasil. \\ ${ }^{4}$ Programa de Pós-Graduação em Meio Ambiente e Desenvolvimento (PPGMADE), Universidade Federal do Paraná (UFPR), Curitiba, PR, Brasil \\ *E-mail de contato: janainamayms@gmail.com
}

Artigo recebido em 26 de dezembro de 2015, versão final aceita em 4 de julho de 2017.

RESUMO: Este artigo tem como objetivo discutir a atuação da Cyklistforbundet (Federação dos Ciclistas) enquanto prática ecossocioeconômica e convivencial. Essa entidade, fundada em 1905, congrega os ciclistas dinamarqueses por meio de projetos voltados à tomada de consciência e mobilização dos cidadãos em defesa dos interesses do ciclismo, em interface com o Estado e diferentes setores da sociedade civil, constituindose em prática ecossocioeconômica na qual promove o bem-viver das gerações atual e futuras. Realizouse revisão bibliográfica envolvendo os temas do ecodesenvolvimento, desenvolvimento à escala humana, ecossocioeconomia e convivencialidade. Trata-se de pesquisa exploratória, por meio de aplicação de questionário à entidade e pesquisa documental em sítios dela, para verificar seu modo de atuação no território. Concluiu-se que a federação passa por metamorfoses concomitantes às transformações da sociedade dinamarquesa, assumindo interesses de setores sociais - com os quais dialoga - de modo a intervir nas questões políticas, culturais e existenciais ao longo do tempo. A Cyklistforbundet tanto reforça a identidade dos dinamarqueses quanto contribui para o fortalecimento da democracia participativa na Dinamarca.

Palavras-chave: Cyklistforbundet; ciclismo; ecossocioeconomia; identidade; democracia participativa.

ABSTRACT: This article aims to discuss the performance of the Cyklistforbundet (Danish Cyclists' Federation) as a practice of eco-social economy and conviviality. This entity, founded in 1905, congregates Danish cyclists and develops projects aimed at raising awareness and citizens' mobilisation, defending the interests of cycling interfaced with the State and different sectors of civil society. Furthermore, this paper does a literature review regarding topics such as ecodevelopment, eco-social economy, human scale development and conviviality. The exploratory research was conducted through an interview script that was applied to the members of the 
Federation and from its website in order to verify your performance in the territory. This study concluded that Cyklistforbundet goes along with the metamorphose of the Danish society by assuming the interests of social sectors - with whom it dialogues - so that to intervene in political, cultural and existential issues. By doing so, the Danish Cyclists' Federation contributes to empower both Danish identity and participatory democracy.

Keywords: Cyklistforbundet; cycling; eco-social economy; identity; participatory democracy.

\section{Introdução}

O presente artigo tem como objetivo discutir a atuação da Cyklistforbundet (Federação dos Ciclistas) enquanto prática ecossocioeconômica e convivencial, mais especificamente evidenciando as contribuições dessa organização não governamental centenária, que atua na Dinamarca em prol da difusão do ciclismo, não apenas como meio de transporte, mas como fator de promoção do bom-viver, quer individual, quer societário. Através da conscientização sobre os benefícios do uso das bicicletas, a federação e seus associados trabalham pela expansão e melhoria das infraestruturas, aperfeiçoamento dos equipamentos utilizados pelos ciclistas e conscientização quanto aos benefícios, interesses e necessidades do ciclismo. Procede por meio de ações descentralizadas de participação de seus associados, na perspectiva da integração social, proteção do ambiente e ampliação da interface entre cidadania e Estado. Contribui, assim, entre outros aspectos, para a realização de um modelo socioeconômico que incorpore as questões ambientais, políticas e sociais na perspectiva de um modelo societário alternativo ao capitalismo dominante.

Trata-se de uma pesquisa exploratória sobre um caso emblemático, centenário, de uma associação de ciclistas na Dinamarca, por meio da aplicação de um questionário a Lotte Malene Ruby, chefe de Comunicação da Cyklistforbundet, no escritório da organização, a 12 de março de 2015, efetuada pelo professor Lars Bohn. Utilizou-se ainda a pesquisa documental em fontes de dados secundários, como informações e documentos disponibilizados no endereço eletrônico da organização. $O$ artigo apresenta, para além desta introdução, as referências teóricas, a caracterização da Cyklistforbundet, juntamente com sua atuação, e considerações finais. Nestas, constata-se que as organizações da sociedade civil contribuem para a construção de identidades e, simultaneamente, para a mobilização dos atores sociais, de modo que estes respondam às questões com que se defrontam em seus respectivos territórios. No seu conjunto, constituem-se práticas que visam assegurar o bem-viver, não somente para a geração atual, mas igualmente para as futuras.

\section{Outro desenvolvimento: ecossocioeconomia}

Há um encadeamento na obra dos autores que discutem a necessidade de superação de uma ordem social liberal, capitalista, mercantil, em direção a uma sociedade que atenda às necessidades humanas, tal como se constitui o esforço denominado ecossocioeconomia. A ecossocioeconomia privilegia o enfoque metodológico-empírico, no sentido de atender ao que será o desenvolvimento sustentável quando assim ele existir no mundo da vida. Diante da dinâmica paradigmática em curso, 
motivada pelo que se intitula de mudanças climáticas, não se pode ser muito rigoroso no processo de transição do velho para o novo paradigma, mesmo porque não se sabe bem quais são seus delineamentos epistemológico-teóricos, por mais que se suponham seus pressupostos (Max-Neef, 2005). A ecossocioeconomia ocorre no mundo da empiria das organizações, seja em grupos produtivos (não necessariamente para resultar em ganhos econômicos), seja em empresas, associações (cooperativas), comunidades e povoados, onde os problemas e as soluções acontecem e nem sempre são devidamente qualificados (Sampaio et al., 2015). Trata-se de uma teoria pensada a partir das experimentações e da complexidade do cotidiano (Sachs, 2007).

$\mathrm{O}$ atual modelo hegemônico é centrado na produção e oferta de mercadorias, sejam elas na forma de bens ou de serviços, cujo acesso depende da capacidade financeira individual para adquiri-los. Ora, as necessidades humanas vão muito além daquilo que pode ser atendido pela compra de mercadorias, no pressuposto de que todos têm dinheiro para acedê-las. Necessidades fundamentais exigem um novo modelo societário que garanta, para além da capacidade de aquisição de mercadorias, a participação política dos cidadãos na definição dos assuntos coletivos e das políticas que atendam às demandas individuais, bem como estratégias de desenvolvimento que respeitem as esferas social e ambiental.

Essa preocupação entrou na pauta política com a realização da Primeira Conferência das Nações Unidas sobre o Meio Ambiente Humano, mais conhecida como Conferência de Estocolmo, realizada de 5 a 16 de junho de 1972 (ONU, 1972). Uma das contribuições relevantes para o debate foi o conceito de ecodesenvolvimento, utilizado pioneiramente em
1973 pelo canadense Maurice Strong, sendo Ignacy Sachs seu mais expressivo utilizador (Mantovaneli Jr. \& Sampaio, 2010). A sua concepção reconhece a necessidade de outro desenvolvimento econômico, direcionado para o atendimento das necessidades humanas fundamentais, com base na participação cidadã, na promoção da autoconfiança e na prudência ecológica, com a intenção de se chegar a um novo padrão civilizatório (Vieira, 2007).

Para Sachs (2007), o conceito de desenvolvimento exige crescimento com justiça social e defesa do meio ambiente. O ecodesenvolvimento é um modelo de desenvolvimento aplicável em escalas locais e/ou regionais visto que, considera e privilegia os recursos disponíveis e as necessidades de cada sociedade, que devem, por sua vez, ser expressas de forma participativa.

Segundo o autor, trata-se de

[...] uma abordagem que postula a busca de estratégias para se promover o melhor uso possível de recursos específicos de cada ecossistema, visando a satisfação, mediante uma grande variedade de meios e tecnologias apropriadas, das necessidades básicas das populações interessadas (Sachs, 2007, p. 106).

Contudo, diante do contexto em que estamos inseridos, muitas vezes a sociedade civil perde o controle do direcionamento do desenvolvimento, em face da enorme influência exercida pelo Estado e pelos grandes complexos industriais. Esses dois atores, no mais das vezes, acabam determinando como as pessoas devem viver. Entretanto, Sachs (2007) entende que a sociedade civil tem capacidade de mobilizar-se em torno de problemáticas socioambientais que envolvam sua qualidade de vida, de tal forma que consiga responder a problemas sociais concretos. Por exemplo, cita-se a Cyklistforbundet, 
que percebe e responde às problemáticas socioambientais ligadas aos transportes urbano e interurbano através da tomada de consciência e da mobilização da sociedade civil, em interface com o poder público e as empresas. Quando aquela está organizada, consegue intervir em questões complexas, como as que tratam do bem-viver das gerações atual e futuras, e ainda manter certa autonomia perante o Estado, o que lhe confere autoconfiança (Sachs, 2007).

Ao se buscar um novo desenvolvimento, conforme Sachs (2007), é necessária a reavaliação tanto dos padrões de consumo quanto dos estilos de vida presentes em uma sociedade. Exigem-se também novas propostas de sociabilidade e atividades lúdicas e culturais. No caso em estudo, a adesão de vastas parcelas da população ao ciclismo denota uma alteração nos padrões de consumo, nos hábitos de locomoção e, logicamente, nos níveis de interação social que essa modalidade de transporte, centrada na bicicleta e no movimento pela construção de ciclovias, proporciona aos seus adeptos. Tal envolvimento da população com o ciclismo requer um novo urbanismo. Portanto, as formas de participação popular, dos usuários, contribuem para a concepção do novo desenho do planejamento urbano e incrementam a politização e o debate social, tanto sobre a cidade quanto sobre o país desejados.

Ignacy Sachs (2007) propôs cinco dimensões do ecodesenvolvimento. Todas elas relevam a sustentabilidade como caráter fundamental do planejamento para o desenvolvimento. A primeira dimensão é a da sustentabilidade social, fundada na construção de uma civilização de acesso mais igualitário à riqueza social, no propósito de reduzir as assimetrias dos padrões de vida das classes sociais. A segunda dimensão, sustentabilidade econômica, requer a destinação e gestão de recursos de modo a garantir mais eficiência na aplicação de recursos públicos e privados. Tal eficiência é avaliada no nível macrossocial, para além dos correntes critérios de rentabilidade social. A terceira dimensão, sustentabilidade ecológica, por sua vez, envolve diversas estratégias para a redução dos impactos ambientais. O objetivo é reduzir o uso de recursos esgotáveis ou danosos ao meio ambiente, como, por exemplo, combustíveis fósseis, substituindo-os por soluções não poluentes que, simultaneamente, promovam a sustentação da vida. Ganha relevo a ética na vida privada e em sociedade, no sentido da autolimitação do consumismo material. A eficiência da gestão dos recursos, conjugada com proteção ambiental, permite o aperfeiçoamento de instrumentos econômicos, legais e administrativos que visem ao desenvolvimento à luz de critérios ecológicos. A quarta dimensão trata da sustentabilidade espacial, ao pretender maior equilíbrio entre áreas rural e urbana, no que diz respeito aos assentamentos humanos e econômicos, reduzindo a concentração em áreas metropolitanas, protegendo ecossistemas frágeis, regenerando práticas agrícolas e aproveitando a capacidade de geração de tecnologias menos impactantes ao meio ambiente. Por fim, a última dimensão é a sustentabilidade cultural, através da qual toda modernização, em qualquer domínio, visa ao resguardo e à continuidade dos sistemas agrícolas, culturas e contextos socioecológicos.

Essas dimensões do ecodesenvolvimento podem ser reconhecidas no trabalho da Cyklistforbundet ao longo de sua centenária trajetória e serão evidenciadas nas etapas seguintes deste trabalho.

Está no domínio da política a chave da reconciliação entre crescimento econômico e desenvolvimento social, pois é por meio de um projeto concebido de forma participativa e democrática que 
se chega à orientação necessária para harmonizar as dimensões do processo de desenvolvimento. Entendida desse modo, a democracia é valor primordial, tanto mais vigorosa quando for direta. Através dela se permitem a expansão das liberdades, a observância dos direitos humanos e o empoderamento, em base de igualdade, dos diversos setores sociais nas tomadas de decisão política, o que proporciona existência decente, segurança contra variadas formas de violência e respeito à identidade cultural (Sachs, 2007).

O debate teórico e político sobre concepções alternativas de desenvolvimento sofreu a intervenção de outros autores, dentre os quais interessa-nos estudar as contribuições do chileno Manfred Max-Neef, propositor da teoria do Desenvolvimento à Escala Humana, cujo postulado ${ }^{1}$ básico é o desenvolvimento de pessoas e não da riqueza material que estas acumulam. O mesmo é concebido no propósito da

[...] satisfação das necessidades humanas fundamentais, na geração de níveis crescentes de autodependência e na articulação orgânica dos seres humanos com a natureza e com a tecnologia, na interação dos processos globais com comportamentos locais, do pessoal com o social, do planejamento com a autonomia e da sociedade civil com o estado. (Max-Neef, 2012, p. 22).

Max-Neef (2012, p. 18), portanto, considera que "[...] o melhor desenvolvimento é $[\ldots]$ o de países e culturas capazes de serem coerentes consigo próprios". Por conseguinte, é pressuposto um regi- ime de democracia direta e participativa, que se coadune com o fortalecimento de uma sociedade civil e com o protagonismo dos cidadãos na construção do futuro, de um modelo societário autodependente.

Esse modelo de desenvolvimento requer, ainda, abordagem inovadora na interpretação da realidade, bem como teoria das necessidades humanas voltada ao desenvolvimento. Para tanto, são necessárias respostas a quatro desafios. Primeiro, internacionalização de uma concepção de desenvolvimento baseada nas necessidades humanas, as quais orientarão ações e expectativas. Segundo, desvendar a origem das patologias coletivas. Terceiro, identificar e analisar as patologias coletivas, pois elas são resultado do contínuo bloqueio das necessidades. E, quarto, fomentar diálogos interdisciplinares, tencionando a compreensão das problemáticas (Max-Neef, 2012).

Dois conceitos importantes, concebidos por Max-Neef (2012), são os de necessidades humanas fundamentais e satisfatores. Aquelas são finitas, poucas e classificadas, não se diferenciam conforme as culturas ao longo do tempo. O que, sim, varia são os modos e meios empregados para satisfazê-las, de acordo com tempo e a respectiva cultura. O não atendimento dessas necessidades implica o desencadeamento de patologias, crises familiares, decréscimo de participação da pessoa como agente social, autoestima declinante e, consequentemente, crise de identidade. $\mathrm{O}$ autor alinha as necessidades em duas categorias: existenciais (ser, ter, fazer e estar) e axiológicas (subsistência, proteção, afeto, entendimento, participação, ociosidade, criação,

\footnotetext{
${ }^{1}$ Princípio fundamental; proposição não demonstrável admitida como válida para ponto de partida de sistema teórico (Japiassu, 1991).
} 
identidade e liberdade). Por fim, as necessidades são satisfeitas em três contextos: individual, social e ambiental.

Os satisfatores são aqueles que atendem às necessidades. Pode ser a uma delas ou a várias. Inversamente, uma necessidade, para ser satisfeita, demanda vários satisfatores. $\mathrm{O}$ autor percebe ainda que é a cultura que define os satisfatores, não as necessidades. É, pois, através de uma mudança cultural que se alteram os satisfatores, inovando ou retomando outros. Exemplifica-se, no caso dinamarquês, com a adoção do ciclismo em desfavor do automobilismo, para a necessidade de locomoção. Os satisfatores são divididos também entre inibidores, singulares e sinérgicos, além de exógenos e endógenos (Max-Neef, 2012).

Tendo em vista os objetivos deste artigo, identificam-se como necessidade a mobilidade, e como satisfator, o ciclismo. Considera-se esse satisfator, por um lado, sinérgico; por outro, endógeno. Sinérgico quando satisfaz simultaneamente uma necessidade específica, porém mobiliza e favorece a realização de outras. É anti-hegemônico, pois trabalha na transformação de valores. É endógeno, pois provém de processos de libertação, a partir de ações deliberadas pelas bases da sociedade. Também eles são anti-hegemônicos.

Outro conjunto de esforços, como mencionado, para pensar o desenvolvimento é a ecossocioeconomia. O desenvolvimento humano está pautado na junção entre "[...] utilitarismo econômico, fruto da dinâmica capitalista, e o chamado darwinismo social, resultado da dinâmica de mercado, ocasionando uma racionalidade social egocêntrica, centrada no cálculo de consequências de ganho individual" (Sampaio, 2010, p. 17, grifos do autor). Essa conjuntura exige pensar uma (ecos)socioe- conômica, ou mesmo uma outra economia, como forma de enfrentamento das incapacidades geradas pelas combinações citadas acima. O autor denomina de ecossocioeconomia das organizações essa nova alternativa.

A problemática ambiental tem sido cada vez mais lembrada quando se trata de desenvolvimento, pois se compreende que o modelo de crescimento econômico não estabelece uma relação consonante com o meio ambiente. Logo, privilegia-se esse crescimento sem considerar a capacidade de suporte dos ecossistemas. Para se começar a pensar em desenvolvimento que inclua a vertente ambiental, Sampaio (2010) sugere superar a sociedade do consumo, bem como superar a constante separação entre sistemas ecológico e social. Para o autor, toda problemática ambiental é social e surge dessa relação, ou seja, de como o social se relaciona com o ambiental. Do mesmo modo, essa é também uma “[...] problemática econômica, social, cultural e espiritual. A natureza propriamente não tem problemas e, se os tem, são inerentes à sua dinâmica e resolvidos por ela (resiliência)" (Sampaio, 2010, p. 38). Dessa forma, compreende-se que os dois conceitos são interdependentes. Existem correntes que privilegiam a natureza (biocentrismo) ou o social (antropocentrismo). Entretanto, esses dois sistemas - ecológico e social - não funcionam “[...] por meio de relações monopolares. Há uma circularidade dinâmica entre ambos" (Sampaio, 2010, p. 40).

A ecossocioeconomia das organizações propõe "[...] a eminência de uma ação extraorganizacional, isto é: o agente organizacional relevando os impactos de sua ação sobre o entorno territorial" (Sampaio, 2010, p. 41). A ecossocioeconomia almeja a substituição do utilitarismo econômico 
individualista e em decorrência do próprio modo de produção capitalista.

Quando se trata da participação dentro de uma organização como essa, Sampaio (2010) sugere que deva ser interorganizacional, mediando tanto os interesses públicos como os privados. A articulação entre o público e o privado pode, segundo o autor, enriquecer a negociação de uma organização, por se tratar de processos participativos. Vale, portanto, destacar que há um campo de disputa, confronto de opiniões e visões de mundo em competição pelos escassos recursos públicos, visando ao atendimento das reivindicações dos respectivos atores sociais.

O desafio da ecossocioeconomia das organizações está em

[...] resgatar princípios da integralidade verdadeiramente humana, que podem ser sintetizados na valorização e preservação de tradições e relações sociais mais solidárias; na geração de trabalho e renda sob a perspectiva de modos de produção mais associativos; no revigoramento dos significados de virtude humana e do próprio Estado, distanciados do racionalismo utilitarista; e na utilização apropriada dos recursos naturais e das capacidades humanas locais (Sampaio, 2005, p. 142).

Ficam evidentes a crítica ao modelo social hegemônico e o resgate de valores sociais pertinentes a uma sociedade solidária, respeitando, nesse sentido, valores e práticas previamente existentes, que estariam ameaçados ou esquecidos.

Sampaio (2010) defende que as organizações precisam atender às demandas sociais presentes no território em que estão inseridas, ou seja, é do território e suas demandas que surgem as organizações. Além disso, as ações das organizações precisam estar ligadas às consequências que legarão para a sociedade. Privilegiarão, então, segundo o autor,

[...] dimensões socioeconômico-ambientais (sustentáveis) para poder corrigir equívocos provocados por um modelo de gestão que privilegia apenas critérios intraorganizacionais (para dentro da organização), baseado numa racionalidade econômica de cálculo de consequências apenas organizacional (Sampaio, 2010, p. 19).

Nessa ótica, a Cyklistforbundet foi criada e atendeu a interesses gerados em determinado território por diferentes atores sociais ao longo da sua trajetória. Destaca-se igualmente a efetividade de uma organização que se concretiza "[...] quando os processos de tomada de decisão revelam as consequências de tais atos à comunidade [...] privilegiando o homem não apenas em sua dimensão econômica [...], mas, também, na dimensão socioambiental, isto é, como cidadão" (Sampaio, 2010, p. 44). Isso só ocorrerá com a participação, seja direta ou indireta, vinculada às consequências dessas ações. Mais especificamente, a participação comprometida. Trata-se de "[...] um sentimento de total responsabilidade na transformação do ideal desejado (visão) em ação realizável" (Sampaio, 2010, p. 44). Dessa forma, entende-se que o processo de tomada de decisão não pode se desvincular de quem sofrerá as consequências dessa decisão. $\mathrm{O}$ autor ainda reforça que as ações dos sujeitos precisam impactar eles mesmos. Isso ocorre, conforme destacamos a seguir, com os membros da Cyklistforbundet - são os próprios sujeitos, singulares e coletivos, que tomam as decisões e por elas são afetados. 


\section{Convivencialidade}

Em 1973, ano do primeiro choque do petróleo, Ivan Illich escreveu dois livros muito elucidativos sobre a configuração das sociedades, condicionadas por distintos tipos de tecnologia e seu regime de propriedade, pelos respectivos usos, quantidades e qualidades das energias que requerem, bem como a maior ou menor equidade social alcançada, decorrente do modelo societário adotado. Illich (1976) interpreta o desenvolvimento como integrante de uma sociedade convivencial, aquela que confere a possibilidade de as pessoas agirem de forma mais autônoma, mais criativa, valendo-se de ferramentas menos controláveis por terceiros. Para ele, enquanto a produtividade concebe-se no sentido de ter, a convivencialidade o é em termos de ser. Nesse sentido, a bicicleta e a própria Cyklistforbundet seriam ferramentas da sociedade convivencial. Conforme suas palavras,

[...] eu utilizo o termo ferramenta no sentido mais amplo possível, como instrumento ou como meio, independentemente de ser produto da actividade fabricadora, organizadora ou racionalizante do homem, ou, [...] simplesmente afeiçoado pela mão do homem para realizar uma tarefa específica, isto é, para ser posto ao serviço de uma intencionalidade. [...] Ferramenta convivencial é aquela que me deixa a maior latitude e o maior poder para modificar o mundo de acordo com a minha intenção (Illich, 1976, p. 38, grifo no original).

Ao especificar de que tipo de ferramenta se trata a bicicleta, o autor classifica-a como manejável a partir da energia metabólica, ou seja, impulsionada e controlada por pés e mãos, e cuja fonte energética é produzida simplesmente por alguém que coma e respire. Para ele, "a ferramenta manejável pode atingir a complexidade de uma organização de transportes, que tira da energia humana o máximo de mobilidade, conforme acontece num sistema de bicicletas e de triciclos [...]". Bem diferente da ferramenta manipulável, a qual é majoritariamente movida por energia exterior, como é o caso do automóvel, que utiliza combustível fóssil. Illich (1976, p. 39) alerta que "[...] a ferramenta manipulável pode exceder a escala humana".

Quando a energia exógena e o uso das suas ferramentas manipuláveis ultrapassam determinada proporção em face do outro tipo de energia de que se dispõe - a endógena e suas correspondentes ferramentas manejáveis -, pode-se exceder a escala humana. Rompido o quantum energético de equilíbrio, para sustentar o industrialismo, criam-se modelos técnico-burocráticos que podem levar ao fascismo, em detrimento das sociedades democrático-participativas. A própria ciência e as suas descobertas são utilizadas para concentrar poder e riqueza em mãos de uma elite. Os custos humanos e ambientais se elevam à medida que o modelo se reproduz e se amplia.

O caminho para romper esse ciclo destrutivo é reconhecer as escalas e os limites naturais que não se deve ultrapassar e trabalhar politicamente para a sociedade evitar o hiperindustrialismo. Será preciso integrar de maneira nova a tríade homem ferramenta - sociedade. Descentralizar o poder e o saber, de maneira a permitir a criatividade de cada pessoa. Esse é o caminho da convivencialidade. Para esclarecer o que é a sociedade convivencial, Ivan Illich (1976, p. 10-12) escreve: "Chamo sociedade convivencial àquela em que a ferramenta moderna está a serviço da pessoa integrada na colectividade, e não ao serviço de um corpo de especialistas. Con- 
vivencial é a sociedade em que o homem controla a ferramenta".

Em outra obra, Illich (1975) aponta para a grande ilusão: acreditar que a energia metabólica humana pode, indefinidamente, ser substituída pela potência da máquina, mesmo que abastecida pelas ditas energias limpas, sem implicar a liberdade e a autonomia das pessoas e das sociedades. Quando isso acontece, elas perdem o controle do seu futuro e se submetem a uma lógica tecnocrática que lhes é de difícil compreensão: a lógica dos instrumentos, da rentabilização em favor dos seus proprietários e da concentração de poder. Então, perde-se a autarcia, "[...] estado de autossuficiência, autonomia diante do mundo externo ou dos estímulos exteriores ao sujeito, inerente ao cultivo filosófico de uma subjetividade tranquila e feliz" (Houaiss \& Villela, 2001, p. 347, grifo nosso).

O simples exemplo do sistema de transporte coletivo baseado no ônibus e no metrô é esclarecedor. O trajeto e o horário do ir e vir por entre uma natureza livre não são mais passíveis de escolha pelo usuário, mas o são por uma administração centralizada, que precisa definir e atender a um mínimo de receita para viabilizar o serviço, seja ele prestado pelo setor privado ou público. A paisagem muda em função da construção de vias automotivas; diminuem os espaços naturais e aumenta a poluição atmosférica; o corpo humano atrofia-se por pouco ou mau uso. Enfim, cai a intensidade da relação do usuário com o ambiente natural, pois ela é mediada pelo motor. Entrementes, aumenta a alienação em face de como se faz a realidade. Desencontrado e exasperado, o passageiro quer mais do mesmo, mais circulação e transporte, porém com mais velocidade, enquanto os custos se elevam. Contudo, o aumento da velocidade e do raio de deslocamento implica aumento da dependência do passageiro em relação ao veículo que o leva, bem como há redução na escolha dos destinos se os engarrafamentos e as infraestruturas precárias não reduzirem forçosamente a velocidade automotiva àquelas dos pedestres ou dos ciclistas. Trata-se, para uns, da capitalização das distâncias; para outros, aprisionamento e dependência da indústria dos transportes, com crescentes gastos de tempo e dinheiro. Os meios de transporte mais velozes frequentemente são mais caros, o que configura uma hierarquia de circuitos de circulação, definindo a classe dos usuários. Onde tempo é dinheiro, a equidade varia inversamente à velocidade. O tempo das pessoas é medido em valor, conforme a velocidade do meio pelo qual se deslocam. O veículo a motor torna seus usuários rivais entre si, por motivo da disputa por espaço, tempo e energia.

É preciso compreender a realidade: mais energia, mais velocidade corrompem irremediavelmente a equidade, o tempo livre, a autonomia - tanto pessoal quanto coletiva - e o ambiente. Os veículos vão conquistando espaço, tempo, vão impondo o seu ritmo ao cotidiano humano. Destarte, uma taxa elevada de energia mecânica leva à redução da igualdade e à limitação da mobilidade urbana. A questão dos engarrafamentos é remediada com pesados investimentos, perda de território natural, recursos humanos e gasto de tempo. Mas isso apenas provisoriamente, pois, a persistir essa lógica, logo sobrevém a saturação.

A energia externa, além do quantum crítico, afirma Illich, corrompe o ambiente social e coloca uma questão eminentemente política: quem controla e decide o que e para quê? O dilema é entre liberdade e convivência versus tecnocracia consumidora de tecnologia com alto consumo energético, concentradora de poder e de riqueza. 
Com uma concepção democrática de desenvolvimento, o povo decide o limite do uso de energia no seu sistema produtivo, de modo a compatibilizar seus valores com a realização dos seus ideais no campo social. Assim, o desenvolvimento dissocia-se do permanente crescimento, um ideal - e simultaneamente uma necessidade - do sistema capitalista.

Para facilitar o discernimento quanto à questão da circulação (deslocamento de pessoas), Illich distingue trânsito de transporte. $\mathrm{O}$ primeiro corresponde ao que os seres humanos fazem com dispêndio de energia muscular, baseando-se no intenso trabalho do corpo humano, que depende de si próprio. Tem valor de uso, não de troca. $\mathrm{O}$ segundo baseia-se na mecânica dos motores para deslocar pessoas e cargas. É produto da indústria e utiliza intensivamente capital, com vistas ao valor de troca (venda dos veículos e das passagens). Quem dele se serve é o passageiro/cliente, sujeito às pressões do mercado. Restringir o trânsito em favor do transporte implica declínio da circulação, situação em que um direito fundamental é prejudicado, o de ir e vir. O monopólio da indústria e do transporte sobre a sociedade, as pessoas e o trânsito, adverte Illich, é atingido quando todos os transeuntes são convertidos em usuários.

Há graves consequências ao se enfatizar o transporte em detrimento do trânsito, as quais vão da destruição ambiental à perda de liberdade, passando por incapacitação das pessoas por falta de exercício, disfunções econômicas e corrosão de tempo e espaço.

Por fim, antes de passar à seção da avaliação do custo-benefício e da qualidade da mobilidade na cidade de Copenhague, cuja contribuição da Cyklistforbundet é incontornável, apreciam-se as ponderações de Ivan Illich (1975) sobre as vanta- gens da bicicleta perante os veículos motorizados, juntamente com sua proposta para uma sociedade justa e democrática.

A invenção da bicicleta significou a possibilidade de potenciar ao máximo o uso da energia metabólica, acelerando a locomoção, e seu alcance, com menos calorias. Percorre-se, assim, mais distância em menos tempo, utilizando-se pouco espaço e pouca energia física, ela própria inerente ao ciclo vital de quem a maneja. A ferramenta é mais barata, mais durável do que o carro e corrói menos território com igual intensidade de acesso. O ciclista é dono de seus próprios movimentos e controla o uso da própria energia, sem estorvar o vizinho. $\mathrm{O}$ cálculo de ocupação de espaço é de um automóvel para 18 bicicletas, com saída de locais congestionados pelo menos três vezes superior à dos ônibus.

Qual será, então, o critério para viabilizar a coexistência de veículos movidos por energia metabólica e por energia exógena (motores)? A resposta é dar prioridade ao movimento humano, proteger a geografia humana contra a velocidade da geografia veicular. O sistema de transporte deve ser subsidiário do trânsito autônomo. Assim, o tráfego (conjunto de trânsito + transporte) pode atingir características ótimas. Como conseguir isso? Só o processo político-democrático pode estabelecer limites para o industrialismo e a velocidade do transporte. $\mathrm{O}$ consumo estrito das quantidades de energia para o tráfego ótimo mostra-se como o caminho para uma era tecnologicamente madura, em que nos libertaremos, quer da abundância, quer da dependência. Mas, para tal ser um desígnio, a decisão política precisa ser tomada pela maioria. 


\section{Cyklistforbundet}

O objeto de estudo - Cyklistforbundet (Federação dos Ciclistas) - está situado na Dinamarca, sociedade de bem-estar social organizada de acordo com o modelo nórdico, isto é, sob o princípio do universalismo. De acordo com esse princípio, os cidadãos com alguma renda contribuem e todos estão habilitados aos serviços sociais, os quais abarcam a educação, a saúde, os cuidados com crianças e idosos, o desemprego, a requalificação profissional, a moradia, entre outros. Os custos são altos, financiados por impostos indiretos igualmente altos, e por impostos de renda progressivos e elevados (de acordo com os respectivos níveis de rendimento). A unidade básica é o indivíduo. Todos os desempregados têm direito a renda de seguridade social enquanto se mantiverem nessa condição. A igualdade e a redistribuição são altas (pensões uniformes). $\mathrm{O}$ fornecimento dos serviços sociais faz com que o setor público empregue $30 \%$ da força de trabalho. As pessoas mais beneficiadas são mulheres, famílias com crianças, estudantes, grupos de baixa renda e aqueles com emprego instável (Andersen, 1997, p. 4).

A sustentabilidade política do universalismo, nos termos recém-apresentados, decorre da extensão dos benefícios também à classe média e aos ricos. Com isso, não apenas se desejava atender aos necessitados com benefícios redistributivistas, mas consolidar para o longo prazo o apoio ao Estado de Bem-Estar Social que, dessa maneira, foi conseguido (Baldwin, 2003, p. 156-7).

\subsection{Antecedentes}

${ }^{2}$ Esse estudo é a base para as informações que utilizamos nesta seção.
Contrariamente ao acontecido na Ásia - em que, dos anos 1970 até o início do século XXI, decresceu o uso de bicicletas e aumentou fortemente a circulação de automóveis, o que contribuiu para os atuais e muito perigosos níveis de poluição atmosférica, como é o caso de Pequim (Reuters, 2015), capital da China, onde as autoridades foram obrigadas a tomar medidas emergenciais -, na Europa verificou-se tendência contrária. Na União Europeia, esforços têm sido feitos para implementar sistemas de transporte mais sustentáveis, em resposta a crescentes preocupações com externalidades, como acidentes, barulho, poluição do ar, mudança climática, a que se recomenda melhor integração com temas como as infraestruturas, a tributação e a tomada de decisões, no quadro dos planejamentos nacionais e da União. A Agência Ambiental Europeia calculou, em 2003, que os custos externos do transporte atingiam $8 \%$ do Produto Interno Bruto dos países da União Europeia (UE), mais Noruega e Suíça (Gössling \& Choi, 2015) ${ }^{2}$. No entanto, curiosamente, a UE não incluiu em tais preocupações o tema da utilização de bicicletas como meio de transporte.

Não é o caso da Dinamarca ou de Copenhague. Lá, várias entidades governamentais, como a prefeitura da cidade, o Ministério dos Transportes e a Agência de Proteção Ambiental, juntamente com entidades não governamentais, escritórios de assessoria urbanística e ambiental, sindicatos, entidades empresariais, pesquisadores e demais acadêmicos, têm produzido estudos em que continuamente debatem e desenvolvem um método de avaliação do custo-benefício (ACB) da matriz de transporte. O primeiro documento estratégico para as bicicletas foi Política da Bicicleta 2002-2012. 
Em 2003, o Ministério dos Transportes compilou, sumarizou e publicou um documento com os métodos avaliativos para calcular custos e benefícios dos projetos de transporte utilizados através do planeta, com o explícito fito de servir de base para o desenvolvimento da ACB de Copenhague. Ele foi seguido por uma série de outros documentos estratégicos que fazem estimativas até o ano de 2025. Documentos bianuais de avaliação também são publicados, discorrendo sobre metas relativas ao incremento do modal ciclístico, com aumento das condições de segurança e da velocidade das ciclovias. Nesse âmbito, são avaliados as percepções dos ciclistas e o grau de satisfação deles quanto ao número, tamanho e qualidade das ciclovias, à sensação de segurança, ao crescimento do número de usuários, bem como à largura e à velocidade que se podem atingir. Nesse domínio, a meta para 2025 é construir superciclovias de três faixas em cada sentido, que liguem as cidades satélites ao centro da capital e permitam dobrar a velocidade média dos ciclistas, atualmente em $16 \mathrm{~km} / \mathrm{h}$, enquanto a dos veículos motorizados deverá permanecer nos $50 \mathrm{~km} / \mathrm{h}$. Os critérios e itens abrangidos pela ACB da prefeitura de Copenhague são vastos e estão permanentemente abertos para incluir sugestões que partam de qualquer setor da sociedade. Aliás, em termos típicos de uma sociedade convivencial, uma grande conquista desse sistema de análise é exatamente o amplo consenso conseguido entre os distintos setores da sociedade local relativamente aos parâmetros e indicadores a incluir na avaliação.

A título de ilustração, incluem-se os itens avaliados, com síntese dos resultados: 1. Custos de operação de veículos: os custos das bicicletassão comparativamente mais baixos do que os dos carros; 2. Custo de tempo: o mais alto custo para os ciclistas3. Custos com acidentes: custos médios de acidentes com ciclistas são incertos, mas, no geral, são mais altos, pela exposição; 4. Poluição atmosférica: bicicletas não contribuem para a poluição do ar. Os custos relativos aos carros são altos; considera-se conservadora a estimativa, pois não inclui cálculo de impacto ambiental nem as incertezas relativas às partículas finas e às substâncias indutoras de câncer; 5. Mudança climática: o ciclismo não incorre em mudança climática. Para carros, os custos com emissão de carbono variam conforme o tipo de combustível e o veículo, mas a média é de $0,170 \mathrm{~kg}$ de $\mathrm{CO}_{2}$ por km; 6. Barulho: bicicletas não implicam custos com barulho. $\mathrm{O}$ desconforto é crescente, com declínio dos preços das habitações em 1,2\% por decibel que exceda 55 $\mathrm{dB} ; 7$. Congestionamento: devido ao menor espaço que utilizam, bicicletas não incorrem em custos com congestionamento. Para carros, variam conforme a hora e o local, calculados em custos de atraso por hora; 8. Deterioração de estradas: bicicletas não incorrem em custos com deterioração de estradas. Para os carros, a deterioração é calculada em 0,001 euro por $\mathrm{km}$ para cada carro; 9. Expectativa de vida e saúde: benefícios do ciclismo para ambas. Os custos considerados são aqueles com tratamento por acidentes e morte prematura. São desconsiderados custos futuros de morte prematura, de doenças em vida, pensões prematuras e morte prematura; 10. Percepção de segurança e desconforto: reconhece-se o sentimento de risco de estar no tráfego, bem como o desconforto ligado à poluição atmosférica, mas seus custos ainda não foram enquadrados na base de cálculo e não foram considerados; 11. Marca e turismo: o ciclismo gera marca de valor para 
Copenhague, considerada a "Cidade das Bicicletas", e tem efeito positivo sobre o turismo. Sobre esse último item, chamam a atenção as considerações da jornalista inglesa Polly Phillips (2015), formadora de opinião que escreve para uma revista voltada a temas de saúde, ao endossar tal divisa e reconhecer que o estilo de vida das dinamarquesas, incluído o "poder do pedal", por utilizarem tanto as bicicletas, as faz ser mais saudáveis, sexy e belas.

A ACB, ao captar tantas variáveis, mesmo não as considerando de imediato, reconhece suas imperfeições, mas é reconhecida no processo democrático de definição social das prioridades. Um exemplo do que falta incorporar são os custos até aqui considerados intangíveis, como no caso de graves acidentes, como a morte de um transeunte e o sofrimento provocado às pessoas próximas, em termos de depressão causada pela perda de ente querido. Não obstante tais ausências, a ACB é considerada muito importante para a mudança da matriz do transporte de Copenhague em favor do ciclismo, que ainda está em curso. A meta é atingir 50\% das deslocações de pessoas em bicicleta, restando os outros $50 \%$ para o transporte coletivo (metrô, ônibus, trem e lancha), mais os carros, na zona metropolitana.

A Cyklistforbundet, atuando a partir da sociedade civil, certamente dá seu contributo à elaboração desses estudos, mas, sobretudo, à formação de uma cultura política participativa, que mobiliza e defende os interesses dos seus sócios e, ao fazê-lo, robustece a democracia no sentido da sociedade convivencial. A seguir, pensamos explicitar isso mesmo.

\subsection{Descrição do caso}

A Cyklistforbundet - inicialmente chamada Dansk Cyklistforbund (Federação dos Ciclistas Dinamarqueses) - é uma organização não governamental (ONG) que trabalha em prol do desenvolvimento do ciclismo na Dinamarca. Ao proporcionar relacionamentos, confiança e troca de experiências entre seus associados, a entidade integra os ciclistas. Estimula, facilita e auxilia-os na proposição de campanhas, projetos e atividades de sensibilização e mobilização do conjunto da sociedade, incluindo o seu estamento político. No entendimento de que o ciclismo deve ser priorizado como meio de locomoção, pela sua capacidade de propiciar bem-viver - o qual compreende saúde às pessoas, além de proteger o meio ambiente -, a federação estimula a participação no debate político relativo às novas formas de organização social, no qual pode sugerir garantia para gerações futuras.

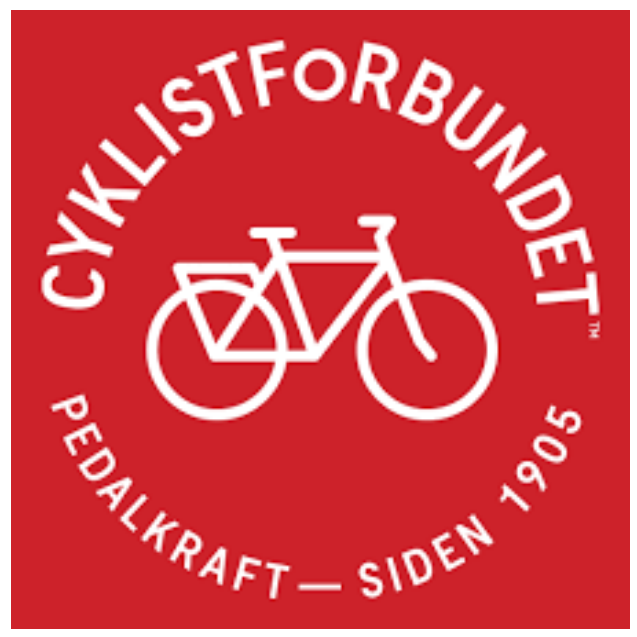

FIGURA 1 - Logotipo da Cyklistforbundet.

FONTE: Cyklistforbundet (2015a). 
Estima-se que cerca de $75 \%$ da população dinamarquesa seja de ciclistas. A sede principal da federação, denominada secretaria, está localizada na capital dinamarquesa, Copenhague. Na secretaria, concentra-se a parte política e administrativa, conjugada a uma loja que comercializa produtos relacionados à atividade. Entretanto, existem mais 40 subdivisões locais (departamentos) espalhadas pelo país. Porém, nem todas possuem endereço exclusivo, pois podem se caracterizar, por exemplo, como reuniões de ciclistas em lugares diferentes, na maioria privados (casas de membros, casas de reuniões etc.). Atualmente, à Federação dos Ciclistas estão associados 16 mil membros. Todos promovem o aperfeiçoamento da política local de trânsito, além de efetuar campanhas e organizar passeios ciclísticos. É interessante destacar que todas essas atividades são realizadas em base local.

As campanhas nacionais promovidas para a conscientização e valorização da bicicleta e da infraestrutura por ela utilizada atingem anualmente cerca de 300 mil pessoas, envolvendo adultos e crianças. As campanhas frequentemente tentam promover o conhecimento e a tomada de consciência das pessoas sobre o ciclismo. Por exemplo, uma enquete pesquisou os comportamentos dos diferentes grupos no trânsito (ciclistas, motoristas, pedestres). Os principais projetos desenvolvidos pela federação são: Alle Børn Cykler, Vi cykler Til Arbejde, LYS $P A-$ med Ludvige Store Cykeldag.

O primeiro projeto citado, Alle Børn Cykler $(A B C)$, isto é, "Todas as crianças andam de bicicleta", é uma campanha para a promoção do ciclismo infantil. Em 2013, ela atingiu cerca de 150 mil cri- anças em idade escolar em toda a Dinamarca.

O objetivo é desenvolver aulas para incentivar as crianças a irem de bicicleta à escola. Além da valorização de um meio de locomoção saudável e barato, as crianças aprendem sobre problemáticas envolvendo questões ambientais, congestionamento no trânsito e, ainda, sobre saúde pública. Segundo a federação, o projeto envolve lazer, seja nas aulas, seja no próprio uso da bicicleta. Ele é gratuito e realizado em parceria com a Fundação Tryg ${ }^{3}$. Um relatório emitido pela Cowi (2015) apontou que o projeto, além de trazer benefícios às crianças, proporciona inúmeras vantagens para a própria sociedade.

O segundo projeto, Vi cykler Til Arbejde (Vc$T A$ ), isto é, "Nós vamos de bicicleta para o trabalho", busca garantir que mais pessoas utilizem esse meio de transporte para ir e vir do trabalho. Também busca promover a saúde para os trabalhadores, bem como diminuir, no país, congestionamentos no trânsito. A campanha acontece desde 1997 e é uma tradição consolidada. Nos últimos cinco anos, o número de participantes variou de 70 mil a 110 mil pessoas. A campanha envolve tanto trabalhadores quanto empresas, pois propõe uma competição entre estas relativamente ao uso da bicicleta, com distribuição de prêmios. Segundo a federação, em 2014, a campanha envolveu 70.888 participantes, divididos em 6.934 equipes. A soma de dias pedalados pelo conjunto de participantes atingiu 827.969 durante o ano de 2014. O projeto é realizado em parceria com a Tryghed i Trafiken - Brancheorganisation for dendanskevejgodstranspor (ITD) ${ }^{4}$ e com os 26 municípios cooperados.

\footnotetext{
${ }^{3}$ Maior companhia de seguros da Dinamarca (Tryg, 2015).

${ }^{4}$ ITD - Segurança no Trânsito - Organização Dinamarquesa de Comércio para o Transporte Rodoviário de Mercadorias (Cyklistforbundet, 2015c).
} 
O terceiro projeto, LYS PA - med Ludvig, "Luzes com Ludvig", dedica-se a contribuir para o aumento da segurança e da visibilidade das crianças no trânsito, através de luzes e refletores nas bicicletas. Segundo a federação, uma a cada seis pessoas, durante a escuridão do inverno, costuma andar de bicicleta sem luz. Isso coloca o ciclista e também os demais (por exemplo, os pedestres) em perigo. A campanha teve início no final do ano de 2014. Todos que se inscrevem na campanha recebem aulas, materiais (cartazes, cartões-postais, catálogos etc.) e também refletores para as bicicletas. A campanha tem fim educacional e, assim como o projeto Alle Børn Cykler, provê muita informação e tarefas recreativas. Além disso, trabalha-se com jogos, quizzes (testes) e demais atividades, tudo em prol da conscientização sobre a visibilidade e a segurança do ciclista no trânsito, evitando-se acidentes.

O quarto e último projeto citado é o Store Cykeldag, "Grande dia do ciclismo". Em 2005, quando do centenário da federação, a título de comemoração, instituiu-se o projeto com a filosofia de anualmente se organizarem dezenas de passeios ciclísticos pelo país, com o propósito de experimentar percursos e apreciar paisagens existentes entre as cidades.

Projetos e campanhas desenvolvidos pela Cyklistforbundet são realizados segundo o espírito, os valores e as práticas de solidariedade, respeito e bom relacionamento com a natureza, de tal forma que se pode considerar que se coadunam com ensinamentos pregados pelos autores precedentemente estudados.

Outra interface da federação com seus associados e o público em geral é a loja que oferece materiais específicos aos ciclistas (bicicletas, roupas especiais, sinalizadores, capacetes, reboque para crianças, literatura pertinente, entre outros). Dessa atividade provêm $16 \%$ das receitas da federação.

A Cyklisforbundet recebe recursos de diversas fontes, como por exemplo, pagamento dos membros, lucro da loja de bicicletas, contribuição da loteria do Estado e ainda por meio de projetos de doadores - em geral cerca de $70 \%$ de privados (fundações beneficentes, ONGs etc.) e 30\% do setor público.

Essa entidade, mesmo não sendo produtora de riqueza material (bens), dadas as suas características e a sua forma de atuação - constatáveis por meio dos projetos acima sucintamente relatados -, evidencia produção humana, com implicações na temática ambiental, o que permite a sua inclusão nos parâmetros da ecossocioeconomia.

\subsection{Trajetória histórica}

Analisando a história da Cyklistforbundet, podem-se verificar vários períodos em que essa federação atuou organicamente em favor daqueles que, no momento histórico, estavam utilizando a bicicleta. Por exemplo, no final do século XIX e início do século XX, membros da grande burguesia, mesmo sem uma estrutura adequada, utilizavam a bicicleta como lazer. Nesse período, o cavalo deixava de ser uma alternativa, em benefício da bicicleta. As pessoas procuravam, então, transformar as trilhas de cavalo em ciclovias e também começavam a identificar os interesses comuns a todos aqueles que utilizavam a bicicleta, na maioria das vezes por lazer e locomoção nas florestas, campos, cidades e assim por diante. Em 1897, dadas as terríveis condições dos caminhos para os ciclistas na Dinamarca, estes fundaram a Cykelstiforeningen (Associação de 
Ciclistas), predecessora da DanskCyklistforbund. Mais tarde, em 16 de outubro de 1905, esta também teve seu nome alterado para Cyklistforbundet. Naquela época, foi estabelecida uma taxa anual para os membros da nova organização, fixada em 1 coroa dinamarquesa.

Segundo Knudsen \& Nicolaisen (2002), as primeiras trilhas foram montadas em valas estreitas, em condições extremamente precárias. Portanto, os objetivos da federação foram ao encontro dos anseios daqueles que utilizavam as bicicletas, que era melhorar as condições de trafegabilidade, transformando os caminhos de cavalos em caminhos de ciclistas, conforme mencionado. Embora a Cyklistforbundet estivesse estruturada, a primeira assembleia geral somente aconteceu em 1936, em um hotel central de Copenhague. Estavam presentes personalidades como o capitão Fritz Hansen, o procurador do tribunal Falbe Hansen, o joalheiro da corte A. Dragsted e também o professor Gabriel Jensen, grande criador e estruturador da federação. Mesmo que a federação tenha sido impulsionada por esse professor, naquela reunião ficou decidido que o primeiro presidente seria o capitão Fritz Hansen, pois, na época, segundo Knudsen \& Nicolaisen (2002), considerava-se que um mero professor não poderia se tornar presidente de uma organização respeitável. Era necessário alguém que pudesse melhor representá-la. Gabriel Jensen ficou então como vice-presidente. Na figura 2, podemos observar, da esquerda para a direita, na primeira imagem, o professor Gabriel Jensen; na segunda, aparecem algumas ciclistas da época; e, na terceira, então, o capitão Fritz Hansen.

\footnotetext{
${ }^{5}$ Cidade portuária do norte da Alemanha.
}

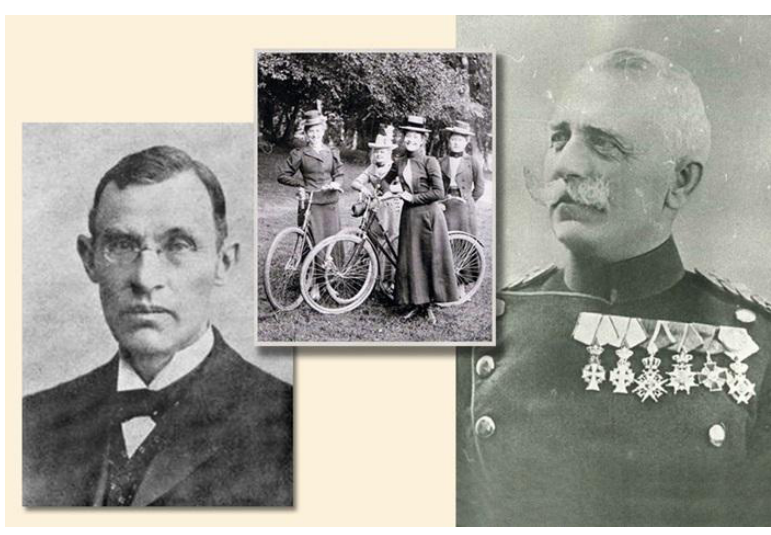

FIGURA 2 - Fundadores e membros da Cyklistforbundet FONTE: Knudsen \& Nicolaisen (2002).

Desde o início da federação, buscou-se juntar uma boa quantidade de ciclistas, para que pudessem pressionar as autoridades, a administração das estradas e o próprio governo local em prol de melhorias para se andar de bicicleta. Entretanto, a Cyklistforbundet sofreu várias críticas e, para muitos, a ideia estaria longe de alcançar sucesso. A organização iniciou com 12 membros. Após uma coletiva de imprensa, no hotel Bristol på Rådhuspladsen, em 1906, a federação passou a receber cerca de 50 a cem membros por dia. Devido à grande aderência de membros, passou a ter um apreciável poder político, em condições, inclusive, de apresentar exigências.

As primeiras ações da organização foram, de fato, pioneiras. Começaram com ciclovias individuais, mas o propósito sempre foi ir além. Gabriel Jensen já havia visto em Hamburgo ${ }^{5}$ listras pintadas sobre os paralelepípedos e queria levar a novidade para a Dinamarca. Criaram-se, então, em alguns lugares, pequenas estações com ferramentas para bicicletas, financiadas através das taxas pagas pelos 
membros. Concomitantemente, faziam-se pequenas ações, como a limpeza das modestas ciclovias. Foi criada, em 1911, por meio de muita pressão, a primeira ciclovia pavimentada. Além disso, a organização lutava para diminuir o número de furtos de bicicletas. Criou-se, em 1916, o Fond til Dusører for Paagribelseaf Cykletyve, "Fundo destinado a prêmios para prender ladrões de bicicleta".

Na década 1930, a federação lentamente mudou. Passou a ser um movimento mais popular, à medida que a bicicleta tornava-se o meio de transporte cotidiano do povo. Esse período é marcado por uma profunda crise econômica mundial, a partir do colapso, em outubro de 1929, da Bolsa de Valores de Nova Iorque. Tal evento agravou a tensão político-social. No inverno de 1932-3, a taxa de desemprego na Dinamarca atingiu seu ápice: ao redor de 43\% (Derry, 2000, p. 319). De acordo com a Cyklistforbundet, nessa época, os trabalhadores assumiram a bicicleta como meio de transporte, o que significou sua popularização e ampla utilização como modal de locomoção.

Nas décadas de 1960-1970, houve uma grande mobilização política na sociedade dinamarquesa, tendo como fundamento posicionamentos políticos de esquerda. Isso também contribuiu para mudar a Cyklistforbundet, que passou a ser mais ativista e militante, ligada aos movimentos em prol do meio ambiente e dos direitos sociais. A federação passa a ter certa identidade e forte influência, quer da esquerda, quer dos ambientalistas, pois passou a ser vista como alternativa aos automóveis. Na época, também havia peremptória política contra a energia e armamentos atômicos, o que a influenciou ainda mais (Rerup \& Christiansen, 2001). É nesse período que o meio ambiente também passa a ser um elemento de mobilização política, tornando a causa das bicicletas ainda mais plausível. Essa conjuntura contribuiu, ademais, para uma mudança na identidade das pessoas, pois passa a ser um motivo de democratização do país, maior participação, mobilização, desalienação, exercício físico e, portanto, bem-viver. Assim, a Cyklistforbundet se caracterizou, nesse período, pela militância na promoção do ciclismo.

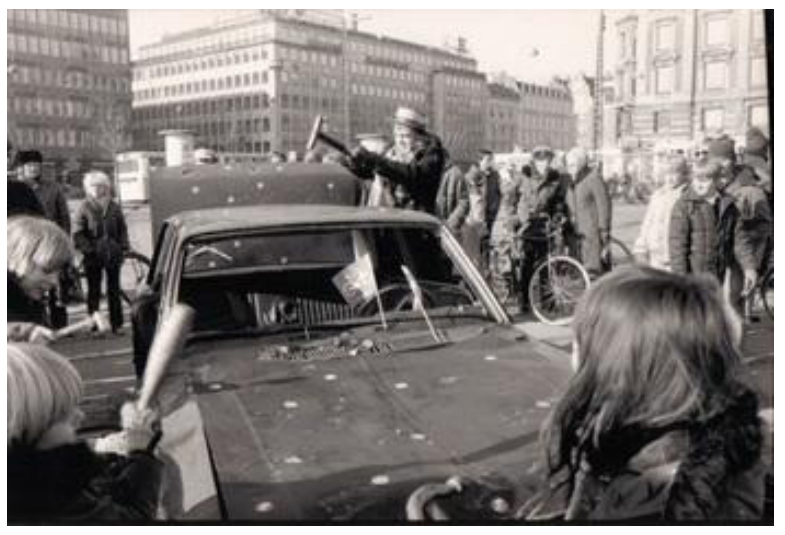

FIGURA 3 - Manifestantes pró-ciclismo batem em um carro velho no Carnaval de 1982: Fastelavn: Slåbilenudafbyen, "Terça-feira gorda: Bater o carro para fora da cidade".

FONTE: Cyklistforbundet (2015b).

Na década 1990, essa mobilização da federação decresceu, e a Cyklistforbundet novamente mudou. Passou a ser menos baseada em militância e a atuar precipuamente como grupo de pressão, mais profissionalizado. Atualmente, o ciclismo é hegemônico, ou seja, não há força política contrária. Partidos políticos, tanto de direita como de esquerda, apoiam a federação. O próprio Folketing (Parlamento) destina verbas significativas para ampliar a infraestrutura ligada ao ciclismo.

No presente contexto, a federação promove igualmente segurança, desenvolvimento de no- 
vas tecnologias, equipamentos e educação para o trânsito de convivência entre pedestres, ciclistas e automobilistas. Hoje, além de não mais existir trabalho de militância política de linha ideológica de esquerda, a federação precisa, ainda, se conter, inclusive abster-se de posicionar-se abertamente a respeito de determinadas questões, exatamente para não ferir as susceptibilidades dos diferentes setores políticos que, de uma maneira ou de outra, apoiam a entidade na promoção dos seus objetivos. Ou seja, atualmente, a Cyklistforbundet trabalha mais apoiando os seus membros nas iniciativas que eles próprios, individualmente, criam. Assim sendo, a federação concede suporte às iniciativas, inclusive conferindo seu nome e seu prestígio. Por conseguinte, com sua pequena, mas eficiente equipe de funcionários, a Cyklistforbundet ajuda pessoas que tomam iniciativas para desenvolver o ciclismo na Dinamarca.

\subsection{Federação nos dias atuais}

Considera-se que a Cyklistforbundet se caracteriza como iniciativa de mobilidade urbana sustentável, pois desenvolve projetos em favor da mobilidade urbana, por meio de bicicletas. Assim, promove a utilização de um meio de transporte que: 1) não agride a natureza; 2) proporciona saúde para a população; 3) reduz o impacto do trânsito no meio ambiente; e 4) estimula a conscientização da população a respeito dessas questões.

Mesmo no contexto mundial de dominância do capitalismo ultraliberal, em que a Cyklistforbundet está inserida, ela consegue identificar diversas oportunidades externas. A principal delas é que sua agenda pela melhoria da saúde das pessoas e pela proteção ao meio ambiente influencia a política de transporte do governo dinamarquês. O ciclismo não é mais uma questão da esquerda, e sim um tema largamente ancorado em todos os campos políticos. Outra oportunidade é a popularidade da bicicleta na sociedade, seja como meio de transporte cotidiano, seja como meio de lazer. Entretanto, a federação considera que isso também pode ser visto como problema, pois o ciclismo, ao passar a ser tão frequente, pode acabar perdendo a atenção devida ou a que possui atualmente. Além dessas oportunidades, a Cyklistforbundet internamente avalia que o corpo profissional envolvido constitui equipe muito idealista, capaz e motivada. Essa coesão de valores entre os membros e as lideranças gera autenticidade. Para a federação, esse é um ponto interno extremamente forte.

Por outro lado, em termos de ameaças, a Cyklistforbundet compete com outros movimentos e causas populares, como meio ambiente, saúde, pobreza e crianças. Essas causas têm foco em grupos considerados mais vulneráveis e visíveis, e por isso conseguem apoio mais facilmente. Outro destaque é que a maior parte dos ciclistas não pensa neles próprios como tais, assim como as pessoas que caminham a pé não se consideram pedestres - portadores de interesses próprios. É difícil, igualmente, ter perfil muito visível, pois as organizações que a apoiam são muito diversas. Finalmente, como fraqueza interna, a federação aponta a falta de recursos próprios e considera poucas as pessoas disponíveis para resolver tantas coisas.

Entre as principais ações implementadas, considera-se uma grande conquista a mudança de agenda do ciclismo: ter transitado de uma questão de esquerda para um assunto largamente aceito por todas as correntes políticas. Assim, o Folketing (o Parlamento dinamarquês) recém-destinou 1 bilhão 
de coroas dinamarquesas (valor equivale, em julho de 2017, a aproximadamente 490 milhões de reais) para o quinquênio que se inicia. Os governos locais, mediante projetos de melhoramento das infraestruturas do ciclismo, ou para fomentar o conhecimento sobre esse modal, incluindo tecnologias de construção de ruas e ciclovias - ao que se soma a educação para o trânsito -, podem fazer uso dessa verba pública.

Percebe-se que a federação impulsiona e garante a geração de conhecimentos voltados ao desenvolvimento do ciclismo e da sociedade democrático-participativa. A sustentabilidade da federação evidencia-se nos mais de cem anos de sua história e na promoção de um satisfator - o ciclismo -, que consegue satisfazer um feixe de necessidades, dentre as apontadas por Max-Neef: afeto, entendimento, proteção, participação, ociosidade, criação, identidade e liberdade. A bicicleta é, portanto, o bem, o objeto material símbolo e a forma de realização desse satisfator. Como o autor aponta, a necessidade é potencial: "A necessidade de participar é um potencial para a participação [...]" (Max-Neef, 2012, p. 34). Ao serem atendidas as necessidades, ipso facto está-se a reduzir as patologias sociais apontadas pelo mesmo autor.

Reforça-se que a Cyklistforbundet fomenta uma cultura de participação e respeito ao meio ambiente, ao mesmo tempo em que utiliza os recursos e potencialidades do próprio território para atender às demandas da sociedade dinamarquesa. Esses são fatores que consolidam o ecodesenvolvimento, pois permitem que uma necessidade societária seja discutida pelos próprios demandantes, de forma participativa, e ainda relevam a dinâmica da natureza no território, utilizando potencialidade local. Dito de outra forma, a Cyklistforbundet interfere em pa- drões de consumo, estilos de vida e interação social, promovendo o diálogo na vida pública acerca das necessidades e possibilidades da sociedade interessada, o que permite ainda a construção participativa de enfoques do desenvolvimento, no qual integra as vertentes ambiental e social.

\section{Considerações finais}

Na Dinamarca, os sinais de trânsito são - como o próprio princípio societário universalista - válidos para todos. Quando o sinal verde se acende, primeiro arrancam os pedestres, depois os ciclistas e, finalmente, os automobilistas. A observância generalizada dessa regra não só garante níveis elevados de segurança de tráfego, mas expressa também uma relação de respeito entre os diferentes. A solidariedade, que garante o funcionamento do sistema social, transmite-se e manifesta-se em todos os campos da convivencialidade, elemento que constitui o bem-viver, particularmente sobre aqueles em que a atuação da Cyklisforbundet primordialmente incide. O modo como pedestres, ciclistas e automobilistas, além dos transportes coletivos - ônibus, metrô, trem e barco -, convivem integradamente quanto ao respeito às normas e aos procedimentos democraticamente definidos traduz a satisfação de várias necessidades, a começar pela identidade, à qual se incorporaram a bicicleta e a cultura que se gerou ao seu redor. Os dinamarqueses e suas bicicletas construíram formas de relacionamento entre diferentes esferas - incluindo públicas e privadas -, de maneira a impulsionarem processos democráticos inclusivos, participativos e autonômicos.

A Federação dos Ciclistas tem uma rica trajetória, que passa por metamorfoses de acordo com 
as transformações verificadas na própria sociedade dinamarquesa, em que está inserida. Uma entidade surgida para atender a interesses, naquele momento, específicos da elite populariza-se durante a Grande Depressão dos anos 1930, quando a bicicleta passa a ser meio de transporte da classe trabalhadora. Como modalidade de transporte popular, desperta o interesse tanto de correntes políticas de esquerda quanto dos ambientalistas. Ambos propugnavam pela difusão do ciclismo, em oposição ao automobilismo e aos danos ambientais por ele provocados. Atualmente, o ciclismo goza de amplo apoio da sociedade, incluída a generalidade dos partidos políticos. A Cyklistforbundet possui trajetória de compreensão do interesse particular enquanto componente do interesse comum, atendendo às necessidades que inicialmente eram exclusivas e passaram a ser inclusivas, ou seja, do conjunto da sociedade. Antes era mobilizadora, agora é plataforma de apoio e projeção das causas que defende.

Ela atende às demandas verificadas nos diferentes territórios em que atua, apoiando os ciclistas associados, os quais autonomamente propõem projetos que visam ao desenvolvimento das regiões onde residem.

Diante da hodierna luta política para manter o Estado de Bem-Estar Social, ou para substituí-lo pelo modelo neoliberal, a Cyklistforbundet tem incentivado as iniciativas individuais e coletivas que fortaleçam a autonomia e a democracia participativa. Como propôs Max-Neef (2012), o ponto de partida é acordar que o melhor desenvolvimento é aquele que incorpore os interesses da geração atual, bem como os das gerações que estão por vir. Em outras palavras, o bem-viver, independentemente da definição subjetiva que pode implicar tal conceito, requer parâmetro coletivo, compreendido como bem comum.

\section{Agradecimentos}

Agradece-se à Cyklistforbundet, na pessoa da chefe de Comunicação, Sra. Lotte Malene Ruby, pela concessão de entrevista.

\section{Referências}

Andersen, J. G. The Scandinavian welfare model in crisis? Achievements and problems of the Danish welfare state in an age of unemployment and low growth. Scandinavian Political Studies, (20)1, 1-31, 1997.

Baldwin, P. The politics of social solidarity: Class Bases of the European Welfare State 1875-1975. Cambridge (UK): Cambridge University Press, 2003.

Cowi. Om Cowi. Disponível em: <http://www.cowi.dk/ menu/home/Pages/home.aspx>. Acesso em: abr. 2015.

Cyklistforbundet. Cyklistforbundet - pedalkraft - siden 1905. Disponível em: <http://www.cyklistforbundet.dk/>. Acesso em: fev. 2015a.

Cyklistforbundet. Højdepunkter fra cyklistforbundets historie. Disponível em: <http://www.cyklistforbundet. $\mathrm{dk} / \mathrm{Om}$-os/Om-organisationen/Historien/nedslag>. Acesso em: abr. 2015b.

Cyklistforbundet. Vi cykler til arbejde. Disponível em: $<$ http://www.vcta.dk/>. Acesso em: abr. 2015c.

Derry, T. K. A history of Scandinavia: Norway, Sweden, Denmark, Finland and Iceland. Minneapolis; London: University of Minnesota Press, 10. ed., 2000.

Gössling, S.; Choi, A. S. Transport transitions in Copenhagen: comparing the cost of cars and bicycles. Ecological Economics, 113, 106-113, 2015.

Houaiss, A.; Villela, M. S. Dicionário Houaiss da Língua 
Portuguesa. Rio de Janeiro: Objetiva, 2001.

Illich, I. Energia e equidade. Lisboa: Sá da Costa, 1975.

Illich, I. A convivencialidade. Mem-Martins, Sintra: Europa-América, 1976.

Japiassu, H.; Marcondes, D. Dicionário básico de filosofia. Rio de Janeiro: J. Zahar, 2. ed., 1991.

Knudsen, W.; Nicolaisen, C. B. Cyklistforbundets historie - de tidlige år, 2002. Disponível em: <http://www. cyklistforbundet.dk/Om-os/Om-organisationen/Historien>. Acesso em: mar. 2015.

Mantovaneli Jr., O.; Sampaio, C. A. C. Governança para o desenvolvimento territorial sustentável. Revista Brasileira de Ciências Ambientais, 18, 77-88, 2010.

Max-Neef, M. Foundations of transdisciplinarity. Ecological Econonomics, 53, 5-16, 2005.

Max-Neef, M. A. Desenvolvimento à escala humana: concepção, aplicação e reflexões posteriores. Blumenau: Edifurb, 2012.

ONU - Organização das Nações Unidas. Declaração da Conferência das Nações Unidas sobre o Meio Ambiente Humano, 1972. Disponível em: <www.mma.gov.br/estruturas/ agenda21/_arquivos/estocolmo.doc>.Acesso em: abr. 2015.

Phillips, P. 7 reasons Danish women look so hot and healthy. 2015. Disponível em <http://www.healthista.com/7-reasons-danish-women-look-so-hot-and-healthy/>. Acesso em: dez. 2015.
Rerup, L.; Christiansen, N. F. Historia. In: Gottlieb, T.; Sehested, T.; Christiansen, M. (Orgs.). Dinamarca. Copenhague: Ministerio de Asuntos Exteriores de Dinamarca, p. 423-497, 2001.

Reuters Brasil. Camada de ar parado provoca primeiro “alerta vermelho" por poluição em Pequim. 2015. Disponível em <http://br.reuters.com/article/worldNews/idBRKBN0TR17K20151208?sp=true> . Acesso em: dez. 2015.

Sachs, I. Rumo à ecossocioeconomia: teoria e prática do desenvolvimento humano / Sachs, I.; Vieira, P. F. (Orgs.). São Paulo: Cortez, 2007.

Sampaio, C. A. C. Turismo como fenômeno humano: princípios para se pensar a ecossocioeconomia. Santa Cruz do Sul: EDUNISC, 2005.

Sampaio, C. A. C. Gestão que privilegia uma outra economia: ecossocioeconomia das organizações. Blumenau: Edifurb, 2010.

Sampaio, C. A. C.; Parks, C. D.; Grimm, I. J.; Alcântara, L.; Fernandes, V. Urban ecosocioeconomics: analysis of experiences of the Northwest of North America. Pullman: Washington State University, 2015. (print)

Tryg. Hvad er Tryg? Disponível em: <http://www.tryg.dk/ forsikringer/hvad-er-Tryg.html>. Acesso em: abr. 2015.

Vieira, P. F. Ecodesenvolvimento: do conceito à ação. In: Sachs, I.; Vieira, P. F. (Orgs.). Rumo à ecossocioeconomia: teoria e prática do desenvolvimento humano. São Paulo: Cortez, p. 9-31, 2007. 